TĀBİRÜ'L-MENĀMĀT'IN SÖZ VARLIĞI

The VOCABLE UNIVERSE of TĀBIR $\ddot{U}^{\prime} L-M E N \bar{A} M \bar{A} T$
Fatma Sibel BAYRAKTAR*

Geliş Tarihi: 09.09.2020 Kabul Tarihi: 03.06.2021

(Received) (Accepted)

ÖZ: Tâbirü'l Menāmāt, Edirneli Hacı Musli/Musalli tarafından 16. yüzyılda kaleme alınmış bir rüya yorumlama kitabıdır. Bu tarz eserlere 'tâbirnâmeler' dendiğini biliyoruz. Tarih boyunca halkın görülen rüyaların ne anlama geldiğini merak edip kendisinin veya yakınlarının hayatları üzerine kurgular yapmasına vesile olan bu görsel fantezilerin bir bilen tarafından açıklanması çok önemli görülmüş, bu anlamda pek çok nazım ya da nesir eser vücuda getirilmiştir. Oriijinali, Kastamonu İl Kültür ve Turizm Müdürlüğü, İl Halk Kütüphanesi, El Yazmaları Koleksiyonunda 37 Kast 4'te kayıtlıdır. Döneminin konuşma diline dair pek çok özelliği barındırdığı gibi arkaik unsurlara da yer vermektedir. Konu başlıklarının çoğunlukla Farsça, bir miktar Arapça ve az miktarda diğer dillere ait olması ve hemen ardından bu başlıkların Türkçe karşılığının verilmeye çalışılması, ayrıca konuların geniş bir yelpazeyi içermesi eseri söz varlığı açısından kıymetli hale getirmektedir.

Toplumsal dilbilim açısından da ayrıca büyük anlam ifade eden bu düş yorumu kitapları, halkın bilinçaltı çözümlemeleri açısından keşfedilmeyi bekleyen birçok sırrı da bünyesinde barındırmaktadır

Anahtar Kelimeler: Tābirnāme, rüya, düş, 16.yüzyıl Türkçesi konuşma dili, söz varlığ⒈

ABSTRACT: Tābirü' 1 Menāmāt is a dream interpretation book written, in the 16th century, by Hac1 Musli or Musalli of Edirne. It is known that these kinds of works are called "tabirnames -dream interpretation manuscripts-." Throughout history, it was considered significant that these visual fantasies caused the public to wonder what the night dreams meant and envisage the lives of themselves or their relatives by a night dreams connoisseurs. Many verses or proses were created in that sense.

The genuine work of the dream interpretation manuscript is full of its many features of the spoken language of the period and archaic elements. The copy of that genuine work is inventoried at the Manuscripts Collection of the Public Library of Kastamonu, under the Kastamonu Culture and Tourism Directorate's authorization. In addition to the fact that the subject titles are mostly Persian and a little bit of them, which also are Arabic, as well as the fact that they belong to other languages in a slight amount. Those titles have been tried to be given immediately Turkish equivalents, as far as possible within Turkish thesaurus; within the feature of being contained in a linguistic broad way, thus it makes the work remarkable in terms of Turkish lexicon.

These dream interpretation works, which also have considered meaning for social linguistics, are also remarkable due to containing many uncharted places on the science waiting to study for the public's subconscious analysis by other related disciplines.

* Dr. Öğr. Üyesi, Trakya Üniversitesi, fsibel@trakya.edu.tr, ORCID: 0000-0002-5699-4572 
Key Words: Dream Interpretation, night dream, dream, 16th Century Turkish Spoken Language, Lexicon.

\section{EXTENTED ABSTRACT}

The dreams, which are an audible and visual perceptual set of emotions, happen in the REM (Rapid Eye Movement) phase of sleep. The fact that people can sense many real and unreal things in their dreams makes that phenomenon even more attractive. Although many functions of the body are off-duty when we sleep, the brain still maintains to process. In this case, some subconscious feelings, thoughts, fantasies, imaginations, worries, fears, passions, and lusts unveil and keep company with cinematographic-like fictions that we call the dream. Some of those are dreams in which the individual has assumptions on what he or she is dreaming and may lead it how he or she wishes. While some dreams may come true later in reality, some dreams are seen as the repeats of the incidents affected in daily life while asleep. Dreams can sometimes be blissful, such as flying, diving from high places to the chasm of the space; however, sometimes those can be scary as the form of nightmares. Whereas some dreams are repeated; some others are seen in the form of a maze, dreams within dreams just like the movie of "Inception."We know that people have been interested; some dreams since the Assyrians in the 5th millennium BCE. Dreams have a crucial role in every religion, belief and society, from the Sumerians to the Egyptians, from the Greeks to the Jewish and Islamic Civilization. In legends, epics, folk tales, the dreams always guide the events and affect those who sense the dreams and to whom the narrator tells about the dreams. Trying to explain the behind the meanings of the dreams, which is to interpret them, is currently seen and maintains its popularity as a fairly common area.The studies arranged to explain the allusions of dreams are called "tâbirnâme." The literature on tabirnames is intense in the Islamic culture and scholar world, indeed. In these works, what the objects and situations seen in dreams will underlie real-life are explained. Indicant things, such as the time, colour, and material cognizance of them, seen in dreams, generally have symbolic meanings. These symbolic values of indicants are, naturally, distinctive according to the dream owner's social position, gender, and nature. These compilations related to the dream interpretations are also precious works to fathom the zeitgeist in the epoch they were written for those reasons. The work called "Tâbirü'l Menâmât," which we are studying on is a dream interpretation book compiled by "Hac1 Müsli (or Musalli), the Edrinopolitan (Adrianopolitan)" in the 16th century. The authentic copy of the book is in the inventory of the Governorate Public Library, Manuscripts Collection of Kastamonu, which is administrating under the authorization of the Kastamonu City's Provincial Directorate of Culture and Tourism. The work consists of 153 sheets. The number of lines per page is generally 20 . The manuscript's calligraphic style is "nesih" and generally not punctuated with vowel points. The work, measuring $240 \mathrm{~mm}$ x $145 \mathrm{~mm}$, is the only and one manuscript copy. There is not any prelude part in the work. After a table of content, which is rendered as a grid, it initials directly into the main topic. Although it states in the description section (which is postscripted by a librarian after) of the manuscript that it is a translation of the tabirname (dream interpretation) of "Muhammad bin Sirin," the names of many other famous dream interpreters are often mentioned in the manuscript. The interpreters mentioned above in alphabetical order are "Câbiri Magribî," "Cafer-i Sâdık," "Danyal Hakîm," "İbrahim Kirmânî." Sometimes, the compilation work applies the folk comments and is indexed as "eydürler kim."For the reason of writing the book, many actions 
and situations and daily objects have lexical entries and have been studied elaborately, depending. The lexical entries typically rubricate in Persian or Arabic, following Turkish thesaural equivalencies and Turkish interpretations. Rarely, borrowings from different languages such as Armenian, French, Italian, Latin, Hungarian, Mongolian, Anatolian Greek and Ionian Greek seems on lexical entries.Sometimes the equivalents for which Persian or Arabic rubrics -should have been in Turkish- also consist of borrowings. Even though the word is a loanword, which also proves to us that the equivalent word is well-known by Turcophone readers, for instance: "destār" (rubric lexical entry, originally Persian)> "dülbend" (equivalent, but originally Persian, too). Sometimes, although the rubric entries in a foreign language are widespread known by Turcophones, Turkish equivalence has also been given by scribes, for instance: " $g a z a \bar{a}$ ” (originally Arabic, but widely known) > "akın" (Turkish). However, the originally Persian entries, by noting " $m a^{c} l \bar{u} m$ " (in English "as is known") at the beginning, are widely known by the public: like the words of "sandal, süsen, tāvus." While some words have happened to Turkish phonological adaptation: "şubān> çobān;" some other words' Turkish equivalents have also been translated into Turkish with Turkish morphological derivation suffixes: "şAdi> şAdllk." There are some examples on Islamic terminology that are turkificated also found in this work: "secde" (or sujud Arabic originally means kowtowing, or prostration): "baş komak" (the verbatim Turkish one means putting one's head down).In the Tabirname, Turkic archaic vocabularies are also found: "bilici, bilig, etmek (ekmek), kaylu (araba), keleci, öküş." There also proper nouns seem, like: "frengistān, şām, tatar, yörük." While beginning to the expression by the phrasal clause as in the example; "görse kim, eger görsekim (English trans. if you see in your dream that);" while stating by the references, for instance; "ibrāhim kirmāni eydür, cābir mag̀ribí eydür [English trans. According to İbrāhim Kirmānī's (or Cābir Magribì's) interpretation];” The last words are usually referred to the sayings from Cafer-i Sādık with phrases like "bu dört dürlüdür, bu dört yön üzredür, tokuz vech üzre yöndür (succinctly in Eng. The dream may be interpreted with four different ways.)" Idioms have a substantial place in that manuscript. On the one hand, expressions like "hāceti revā ol- (in Eng. to have what she or he desires), düşmen şerrinden em in ol- (to be safe against the evil or/and the evildoer)" in positive comments in the work, on the other hand, expressions like "gusșalu ol- (being in trouble), gusssaya giriftār ol- (being overwhelmed by a calamity)" in negative comments are common.The work, which is penned colloquially in order to inform the public about the symbols that stand for the dreams to correspond for reality, has a sincere literary style. Thanks to discussing topics and cases in every division of life, both usual and unusual situations, the work has a large and exciting vocabulary. Besides, it also draws attention as a wide-ranging work that offers us multifarious sociological research objects with its life perspective of the era in which it was written, human affairs, interpretations that differ amongst genders and social levels.

\section{GIRISS}

Arapça rüya, Türkçe düş(<tüş); insanlık tarihi boyunca görenin ifadesinden başka kanıtı olmamasına rağmen ciddiye alınıp üzerine mitler, efsaneler dahi üretilen önemli bir olgudur. Hâlâ nasıl olduğu, gözler kapalıken nasıl görüldügü tam olarak 
açıklanamamasına rağmen, tarih boyu görülen rüyaların ne anlama geldiği, iyi ve kötü, basit ve seçkin rüyalar gibi sınıflandırılmaya, anlaşılmaya çalışılmaktadır.

M.Ö. 5 binli y1llarda Asurlular döneminden beri insanların rüyalara ilgi gösterdikleri bilinmektedir. Sümer tabletlerinde de rüya tabirlerine rastlanmaktadır. MÖ 2000-1800 yıllarında Mısır'da yaşamış 12. Sülaleye ait bir papirüs, tespit edilen en eski rüya yorumu kitabı sayılmaktadır. Yunan ve Yahudi medeniyetlerinde de Asur ve Mısırlıların rüyaları yorumlama metotlarının takip edildiği görülür. İslam medeniyeti de rüyalara önem vermiştir. Bilindiği üzere Yakup'un (a.s.), Yusuf'un (a.s.) rüyaları üzerine pek çok eser kaleme alınmıştır.

Türk kültüründe de rüyalar son derece önemli kaynaklardır. Efsanelerde, destanlarda, halk hikâyelerinde, âşıklık geleneğinde rüyalar önemli rollere sahiptir. İslamiyet'ten önce ve sonra bu önem kesintisiz devam etmiştir. Türk destanlarındaki rüyaların en önemli işlevi gelecekteki olayları önceden haber vermesidir. Uygurların Türeyiş Destanı'ndaki Bögü Kagan'ın rüyası, Uygur harfli Oğuz Destanı'nda Uluğ Türk tarafindan görülen rüya, Şecere-i Terâkime'de Toğurmış adlı şahsın rüyası vb. hep böyle kozmik işaretlerle doludur.

Gökyay'ın (1982: 183) çalışmasında belirttiği gibi; Türkçede rüya ile ilgili "ağır basma, düş azmak, düş görmek, düş yormak, kara basan, kara düş, kara kaygılı rüya, karakura, karakura basan, karakura basmak, karakura düş görmek” gibi deyimler bulunmaktadır.

Mutasavvıflar da rüyaları önemli bulup sınıflandırmışlardır. Onların sınıflandırmalarına göre rüyalar: sadık veya nefsanî rüyalar diye ayrılabildiği gibi basit ve seçkin rüyalar diye veya Allah'tan, melekten ve şeytandan olanlar (Tatçı ve Çeltik, 1995: xiii) diye sınıflandırılıp değerlendirilebilirler.

Görülen rüyaları bu kadar ciddiye alıp sınıflandırmalara tabi tutan insanlık bu konuda edindiği bilgi ve tecrübelerini de gelecek nesillere aktarmayı bir görev bilmiş, bu konuda birçok eser kaleme almıştır. Görülen rüyaların ne anlama geldiğini açıklayan eserlere ta'bîr-nâme, ta'bîrât-1 vukūât, ta'bîrât-1 rü'yâ, rü'yâ-nâme, vâkıanâme, segir-nâme, güzâriş-nâme gibi isimlerin kullanıldığı da görülmektedir (Gökyay\&Coşkun;2010).

Genellikle mensur yazılmalarına rağmen manzum olanları da bulunmaktadır. Agâh Sirrı Levent'in ifadesiyle halka hitaben yazıldıkları ve sanat kaygısı gütmedikleri için rüya yorum kitaplarının dilleri açık ve sadedir. Günlük konuşma dilindeki birçok kelimeyi ihtiva ettikleri için de özellikle sözlük çalışmaları ve dil tarihi açısından önemli bir kaynak oluşturmaktadırlar. Ayrıca tābirnâmelerde günlük yaşamın yanında halk inanışlarının da yer alması bu eserlerin kültürümüz açısından da önemli bir kaynak olduğunu ve bu konularda çalışanlara kaynaklık edebileceğini göstermektedir (Levend, 1988: 166). 
Trakya Üniversitesi Sosyal Bilimler Dergisi

Haziran 2021 Cilt 23 Sayı 1 (493-508)

\section{ESER HAKKINDA BILGI}

Bu eser Edirneli Hacı Muslî tarafından H.991 (M.1582) yılında kaleme alınmış "Tâbirü’1 Menâmât" adlı bir rüya tābirnâmesidir. Eserin baş tarafinda: "1. Kastamonu'da Kırkçeşme Mahallesinde Şeyh Ahmet Siyahi'ye ait bir adet mühür var, 1295. 2. Halidiye Medresesinden devren alınmuştır. (Halidiye 593)" Açıklamaları yer almaktadır. Eser 153 varaktır. Satır sayısı genellikle 20'dir. Yazı türü nesihtir ve genel olarak harekesizdir. Ölçüleri 240x145mm.dir. Eser tek nüshadır ve bir ciltten ibarettir. Adem Balaban tarafından yayınlanan "Türkçe Yazma Tâbirnâmeler" adlı makalede 37. Tâbirnâme olarak bu eser zikredilmekte ve müstensihi "Edirneli Hacı Musalli" olarak verilmektedir (Balaban, 2014: 122).

Her ne kadar açıklama bölümünde Muhammed Bin Sirin'in tâbirnâmesinin çevirisi olduğu bilgisi yer alsa da eserin maddelerinde başka önemli şahsiyetlerin rüya tabirlerinden de atıflara başvurulmaktadır. $\mathrm{Bu}$ şahsiyetler diğer rüya tâbirnâmelerinde de sık sık zikredilen Muhammed Bin Sîrîn, Danyal Hakîm, İbrahim Kirmânî, Câbiri Mağribî, İsmail Eş'et ve en çok atıf yapılan Cafer-i Sādık'tır. Kimi zaman tanınmış yorumculara değil halk arasında söylenegelen kalıplaşmış yorumlara başvurulduğu da olur. Eser bu durumda bir kopya eser değil, derleme mahiyetindedir. Başta 14 yaprakta fihrist vardır. Eser "bâb" esasına göre kaleme alınmıştır. Bâblar Osmanlı alfabesinin sıralamasına göre harf sayısınca düzenlenmiştir.

Elimizdeki eserde herhangi bir giriş bölümü olmaksızın ızgara sistemli fihristten sonra doğrudan konuya girilmektedir. Birçok tâbirnâmede görülen konularına göre sınıflandırma sistemi bu kitapta uygulanmamıştır. Konular Osmanlı alfabetik diziliş dikkate alınarak sıralanmıştır.

Eser genel olarak harekesizdir. Ancak yazarın birkaç kez yazı karakterini değiştirdiği ve kimi sayfalarda hareke kullandığı da gözlenmektedir.

\subsection{Madde Başları}

\section{ESERİN SÖZ VARLIĞI}

Madde başları büyük bir çoğunlukla Farsça olduğu için konuların gelişi de Farsça adlarına göre sıralanmıştır. Kırmızı mürekkeple Farsça veya diğer dillere ait başl1ktan sonra Türkçesi de verilmektedir; şebpere: yarasa 93b/1, sinne: gögüs 91a/4, simm: gümüss 91b/5, şehādet: tanıkluk vermek 97b/3 vb. Ancak Arapça madde başları da kayda değer sayıdadır. Bunun yanında eser miktarda yani oldukça az sayıda Ermenice, Fransızca, Latince, İtalyanca, Macarca, Moğolca, Rumca ve Yunanca madde başları da görülür.

Bazen madde başı ve onun açıklamasının her ikisi de Türkçe değildir. Kimi zaman madde başı Farsça, açıklama Arapça; kimi zaman da madde başı Arapça, açıklama Farsça veya başkaca bir alıntı dilden olabilir: 'azāde: terkî 105b/6 (Far+Ar), fakiḥ: dānişmend 110a/7 (Ar+Far), ḩāme: ḳalem 52a/14 (Far+Ar <Yun), 
kāfile: kārvān 111b/16 (Ar+Far), ḳaz: ibrişim 112a/7 (Ar+Far), kilid: anahtar 124b17 (Far+Rum), șahiffe: nāme 100b/7 (Ar+Far), sîmurğ: 'anka 91b/14 (Far+Ar), zen: 'avrat (Far+Ar) vb.

Bazen Farsça bir madde başının yine Farsça ile izah edildiği veya Arapça bir madde başının yine Arapça bir sözcükle açıklandığı görülmektedir. Bu türden madde başları sayesinde çağında Türkçeye girmiş Arapça ve Farsça sözcüklerin hangilerinin yaygın kullanıma sahip, hangilerinin terim mahiyetinde olduğu da açıklığa kavuşmaktadır; destār: dülbend 62b/18 (Far+Far), durrā'a ferāce (Ar+Ar), hatene: sünnet (Ar+Ar), hibr: mürekkep (Ar+Ar), sim āb: jiva (Far+Far) vb. Bazen de Arapça bir sözcük Farsça fiil ile birlikte başlık olarak kullanılmıştır; șadaka_dāden 100b/15, tevbe kerden 41a/20.

Bazen madde başı Farsça iken açıklama sadece ek alarak Türkçeleşmiştir; şādi: şādlık 92b/1. Bazı Farsça başlıkların Türkçeleri sadece fonetik değişime uğramış ve Türkçeleşmiş sözcüklerdir; şubān: çoban 92a/10, ġırbal: kalbur 108b/3 vb. İslami terminolojinin Türkçeleştirilmiş örneklerine eserde rastlamak mümkündür: secde: baş komak 79b/15, munādì: kı̀g ırdıcı (müezzin)142a/5.

Kimi madde başlarının halk arasında Farsçaları bilinmesine rağmen Türkçe açıklamalarının da verilmesi tercih edilmiştir; gazā: aḳın 108/b7, şalvar: düz ton 95a/6 vb. hatta alıntılanan sözcüğün kendisi ve Türkçeleşmiş şeklinin birlikte kullanıldığı da olur; keşiş țonı olursa meyli käfirlıga ola eger gavur țonı olursa... 43b/8. Ancak çoğunlukla madde başlarındaki Farsça adlar halk tarafindan biliniyorsa "ma' lüm" diyerek doğrudan konuya girilmektedir. Örneğin sadef, sandal, süsen, şatranç, şi'r, tâvus vb. madde başlarının ayrıca Türkçe kökenli bir sözcükle açıklanmasına gerek duyulmamıştır. Bu şekilde ma' lūm diyerek yaygın kullanıldığı beyan edilmiş olan bazı madde başlarının günümüzde kullanımı ortadan kalkmış bulunmaktadır; 'ases: ma'lüm, fukāa': ma'lüm, 'üd: ma'lüm vb. Eserde, geçen zaman içinde dilimizde kullanımdan uzaklaşmış birçok sözcüğün izini bu vesileyle sürmek mümkündür.

Bazen de bir sözcüğün Türkçeye değişik çağlarda girmiş biçimleri ya da değişik yollardan alıntılanmış biçimleri bir arada görülebilmektedir: levzīi bayām 131b/5, bādem 15b/9; bādincān /badlican 16b/15.

\subsection{Arkaik Sözcükler}

Eserde arkaik sözcüklere sıkça rastlanmaktadır. Allah sözcüğündense Tarrı sözcüğü daha çok kullanılmıştır. Birçok kez Arapça teâlâ sözcüğü ile birlikte Tayrı teâlâ şeklinde ifade edilmiştir. bilici ('alim) 105a/1, bilig 25a/17, etmek (ekmek) 111b/1, lddı 79a/15, kabala: kadı bitisi 111a/13, kakl-111b/2, kalıca 111a/2, kande 22b/17, kanḳı 22b/18, karaġuluk 109b/17, kạlu (araba) 119a/3, katı (çok) 89b/4, 
keleci 22a/17, konşı, kurı 112 b/6 (bu başlık Türkçe olmasına rağmen unutulmuş bir sözcük olmalı ki açılaması da "kuru et" olarak yapılmıştır), öküş16b/18, saǵu sag̈ur-149b/8, söyün- 96a/10, süci 112a/3, tamu100a/10, uggr 109a/10, ur-54a/19, yegrek110b/12, yayın(yazın) 21b/10 gibi sözcüklere eserde sıklıkla rastlanmaktadır. Kullanılan sözcüklerin bazıları Tarama Sözlügü’nde geçen şeklinden farklı bir formda karşımıza çıkmaktadır. Söz gelimi Tarama Sözlüğ̈̈'ndeki yavu kılmak sözcüğü eserde yavurmak şeklinde geçmektedir. Bazı sözcüklerin Türkçesinin kullanımdan düştüğü, yerine alıntı bir sözcügün kullanım sıklığına ulaştığı eserin dilinden anlaşılmaktadır. Sözgelimi àyine 15a/11 başlığından sonra Türkçesi gözgi olarak verilmiş ancak madde ayrıntılı olarak açıklanırken āyine sözcüğü kullanılmaya devam edilmiştir. Bu da eserin yazıldığı dönemde gözgü sözcügünün söndüğünü onun yerine āyine sözcüğünün işleklik kazandığını bize göstermektedir.

Eski Anadolu Türkçesinde sık kullanılan ve günümüzde unutulan kimi eklere de eserde rastlanır; +cIlAyIn yapım eki; ancllayındur 14a/17, buncılayın 6a/19; +rAk karşılaştırma eki artığırakdur 132a/7, eksügirek 132a/6 vb.

\section{3. Özel İsimler}

Eserde birç̧ok özel isim kullanılmaktadır; Allah adı yanında Tañrı sözcüğü de sık sık tercih edilmektedir. rūstā (köy) maddesinin karşılığ türklük olarak açıklanmıştır. Yani Türk olmak köylü olmak anlamına gelmektedir. şehristān maddesinde hindiyā şarları, horzum şehri horistān, 'irak, kirmān, hicāz, yemen, mı șır, şām, rum, magrrip ve frengistān şehir adları zikredilmektedir. dicle, firat, nil, itil ırmakları yorumlarda yer almıştır. tatar 8b/9, yörük 108b/9 ve 'alevi $93 \mathrm{a} 717$ adları da birer kez geçmiştir.

\subsection{Kalıp İfadeler ve Deyimler}

Tıpkı deyimler, atasözleri gibi belirli durumlarda söylenegelen ilişki sözlere kalıp ifadeler denmektedir. Her toplumun belirli durumlarda kullanılması âdet hâline gelmiş kalıp ifadeleri olduğu gibi konuşma dilinde şahısların ve yazı dilinde eser sahiplerinin sık kullanarak kendine özgü bir üslup oluşturdukları özel kalıp ifadelere de rastlamak mümkündür. Bu eserde de cümleler genellikle görsekim veya eger görsekim, kalıp ifadeleri ile başlamaktadır. Rüyada görülmesi muhtemel varyantlar yazarın görüşüne göre sıralanmakta ve her sefer yorumlanarak diğer ihtimale geçilmektedir. Bu gibi durumlarda ola kim kalıbının da kullanıldığı görülür.

Referanslara başvurulduğunda da ibrāhim kirmāni i eydür, cāfer-i șādlk eydür, cābir mag̀ribi eydür, muhammed bin sìrin eydür, dānyāl ḥakīm eydür kalıp ifadesiyle açıklama yapılmaktadır. Referans kulaktan dolma ise eydürler kim şeklinde cümle başlatılmaktadır.

Yorumlara geçildiğinde ise bu dört dürlüdür, bu dört yön üzredür, tokuz vech üzere yöndür gibi kalıp ifadeler kullanılmaktadır. 
Rüyada görülen durumun ya da şeyin olumlu bir şeye veya duruma delil sayılmasına karşı en sık kullanılan deyimlerden biri de hăceti revā ol- 47b/16 kalıbıdır. Bunun yanında olumlu neticeler için; düşmen şerrinden emin ol- 40b/8, düşmen üzerine ġālib ol-47b/6, düşman üzerine zafer bul-97a/3, düşmanına zafer bul-118b/6 gibi deyimler kullanılmıştır.

Rüyada görülen durumun ölüme delalet ettiğini anlatmak için benzer ifadelere başvurulmuştur; eceli gel-38a/1, ecel yakın gel-33b/6, eceli yakındur 37b/5, ecel yakıı ol-43a717, ecel yakın gelmiş ol-78a/5.

Tâbirnâmede görülen rüyalar kötü bir duruma ya da kötü bir durumdan kurtulmaya delilse bunun açıklaması genellikle ġușsa sözcügü ile oluşturulmuş ifadelerle verilmektedir; gușșa git-101a/1, guș̦salu ol- 93b/11, gusșsaya giriftār ol-

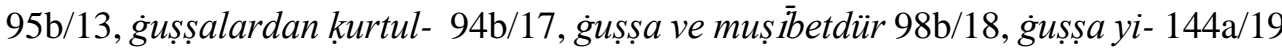
vb.

Eser bir tâbirnâme olduğundan halkın anlayacağı bir dille yazılmıştır, bu nedenle zengin bir deyim dağarcığına sahiptir; anıñ avicından ululuk bul-106a/3, așșl gör- 117a/1, bay ol- 96b/14, baş ko- 79b/15 el çek- 28b/18, emin ol- 28a/7, dín yolu bulmuş ol- 93a/8, dört ayaklyya bin-12b/6, , elin dine ur-113a/19, hased eyle96a/11, hạṣ̂l ḳ1l- 89b/19, iş tut-101a/11, işi yürü- 116a/13, māl düşir-114a/11, maksūudına ir-113a/21, murādına deg-, 112a/19, ‘ömri uzun ol-96b/15, rāhat deg110a/7, ululuk bul- 96b/6, yüzün evine tut-111b/20 vb.

Eski Anadolu Türkçesinin etkilerinin kuvvetli olarak görüldüğü eserde yardımc fiillerle birçok deyim ve kalıp ifade oluşturulmuştur. 'gör-' fiili ile pek çok olumlu ve olumsuz anlamlı deyim bulunmaktadır; așșı göre, eylik göre, güc göreler, fāyda göreler, hayr göre, rạ̣met göre, zahnmet göre vb. 'git-' fiili ile olumsuz anlamlı pek çok deyim üretilmiştir: díni gitmekdür 18b/11, elden gitmişs ve yitmiş 153b/15, heybeti gitmeye 13b/20, ussl gitmek 36b/3 vb. 'deg-' fiili de deyim yapmakta sık tercih edilen bir yardımc fiildir; așșı dege 23b/5, gusșa dege 22b/4, mażarrat dege 23a/9, meserret dege 27a714, renc dege $27 \mathrm{a} / 16 \mathrm{vb}$.

\section{5. İkilemeler}

Sözün anlamını pekiştirmek, vurgusunu artırmak, değişik anlam ilgileri kurmasını sağlamak amaciyla oluşturulan ikilemeler eserimizde de kendisine yer bulmuştur. Ad soylu ikilemeler yanında, iki eylemin art arda meydana geldiğini anlatan ikileme şeklinde fiillere de rastlanır: $a z$ az 3a/3, ḥarām ḩavār 112a/4, dürlü dürlü 115a/8, hadsiz endāzesiz 115a/10-11, ald yedi 71b/13, düşdi öldi 35a/15, tutdı aldr $23 \mathrm{a} / 4 \mathrm{vb}$.

Eserde aynı sözcüğün farklı dillerden alıntılanmış olanları ve Türkçeleri birlikte kullanılarak sözlüksel malzeme zenginleştirilmiş, ikileme ve üçlemeler 
yapılmıştır; behişt, cennet,.. uçmag $31 \mathrm{a} / 2$, lägari arıklık ...Ża'íflig 152b/1, 'ākıbet son1 yatlu ola 43b/6, işleri revān ola yürüye 132b/16, kan revān aḳar 80b/12, țalāk virüb boșaya $147 \mathrm{~b} / 1 \mathrm{vb}$.

\subsection{Bağlaçlar}

Türkçe, Arapça 've' bağlacını kullanmak yerine iki sözcüğü araya herhangi bağlayıcı bir sözcük koymadan kullanmayı seven bir dildir. Bu anlamda eserde alıntı ve Türkçe sözcüklerin yan yana getirilerek ya da anlamca birbirine yakın sözcükler gruplaştırılarak güzel bir anlam ahengi kazandırılmaya çalışıldığı gözlenmektedir; belāya afete uǵraya $3 \mathrm{a} / 2$, eger toǵan elinden boșansa tașması elinde kalsa $17 \mathrm{a} / 19$,

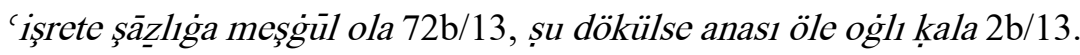

"ve” bağlacı eserde nispeten az kullanılırken büyük çoğunlukla "yā" bağlacı ile nesneler ya da durumların arka arkaya sıralandığına şahit olmaktayız: bïm ve korkudur 15b/17, bir iş işleye kim tamām olmaya ve 'izzet eksile110b/14, ḳavi ve muhkem ve beklenmiş ola 85b/20, menfa'at ve așș 101b/5, nāmübarek ve şomdur $33 \mathrm{a} / 5$, renc ve 'azāb ve mihnetdür $82 \mathrm{a} / 13$, șavaş ve çekişikdür $110 \mathrm{a} / 15$, şāạllı̣ ve hurremlik 24b/12. 'bir tağdan yā belekden yā dam üstünden yā bir yüksek yerden 110b/13, hizmetkār yā emīnlik yā șalāḥdur 17a/14, ḳarındaşdur yā og̉uldur 17b/8, pamukdan yā yüg den iplik egirür $73 \mathrm{a} / 5$.

Bunların dışında sık rastlanan bağlaçlar:

ammā: 'avratı bunı seve ammā rüsvā ola 71a/14, og̀l1 tog̉a ammā ki öle 68b/17, zahm görse ammā kan olmasa 75a/7.

hem: ḥalvā hem māldur 51a/3, hem dīnde hem dünyāda 56b/9, hem hayrdur 65b/15. ile: 'avratile 68b/6, genezligile 66b/16, zahmetile 66b/15.

yāhūd: hacca vara yāhūì șayruluḳdan kurtula 50a/2, öleler yāhūid bir āfete uğrayalar 64b/18, yā müselmān ola yāhūid öle 48b/7.

\subsection{Fiilimsiler}

Türkçede fiilimsilerin kalıcı adlar yapmada aktif rol oynadıkları bilinmektedir. 15. yüzyıla ait bu eserde de bilhassa sıfat fiillerin kalıcı adlar yaptığı birçok örnek bulunmaktadır.

3.7.1. Ad Fiiller

bogmak (gerdanlık) 103a/5, etmek (ekmek) 30b/13 vb.

\subsubsection{Sıfat Fiiller}

Türkçenin her devre ve sahasında olduğu gibi işlektir. Adlaşmış örnekler çoktur: ta'am: yiyesi 102a/21, -dIk/-mAdIk sıfat fiilleri günümüz Türkçesine göre daha çok kullanılmaktadır: doḳunmaduk yüy 27a/3, güneş kararduğ 109b/19, ummadugí1 yerden 32b/10, reşid olmaduk og̉landur 45b/1 yanmaduk mum 96a/11, 
yanmaduk kandil 113a/18. Diğer sıfat fiiller de eserde aktif olarak yerini almıştır; sig̀ncak 111a/ 5, ādemlere karışmaz er 111a/16, kur ān bilmez oḳısa 89b/9, nemāz kılmaz dinsüzler $89 \mathrm{a} / 1$, olmaz işler $59 \mathrm{a} / 5$, aḳar su $8 \mathrm{a} / 14$ yanar od $4 \mathrm{~b} / 16$, odulmış 4b/16, șınmış sü̈ ük 9a/5, bitmiş kandīl 114a/13, binecek 122a/6, dikecek kaftānları 65b/17, mihbere: mürekkeb konacak 135b/17 vb.

ol- yardımcı fiili ile oluşturulan karmaşık fiillere de eserde sıkça rastlanmaktadır; dìn yolu bulmuş ol- 93a/8, istig̈fār idecek olursa 9a/7, ivecek ola 40b715, yas dutar olalar 43a/10 vb.

\subsubsection{Zarf Fiiller}

dutu ko- 120a/14, göre 71b/18, gördüginleyin 67b/6, otururken $12 \mathrm{~b} / 4 \mathrm{vb}$.

\section{SOSYAL İÇERİK}

Yazarı tarafından halka yararlı olmak amacıyla kaleme alınmış olan eserde hem madde başlarının yabancı kökenli sözcüklerle başlaması hem bu sözcüklerin Türkçe karşılığının verilmesi sayesinde eser 16. yüzyılın yazı dili ile konuşma dili arasında bir yerde konuşlanmış bulunmaktadır. Anlaşılır olmak gayesinin ön plana alındığına şüphe yoktur. Eserin sonuna doğru konuşma dili baskın hâle gelmiştir; eysesi olsa ko söylemeye 102b/4, vallah 'ālim ta birdür hā 153a/20.

Diğer tâbirnâmelerde olduğu gibi bu tâbirnâmede de rüyaları gören asıl unsur elbette ki erkeklerdir. Rüyanın yorumlanışı öncelikli olarak bir erkeğe göre yapılır ve bu genellikle birgü 90b/2, birgüsi 113a/11 gibi bellirsiz zamirlerle verilir. 'Erkek' sözcüğü kullanılmaz onun yerine 'er' kullanılır eger bir er görsekim süd emer 98b/7. Erkeklerin dünyasında sosyal sınıflar görülen rüyanın doğru yorumlanabilmesi için son derece önemlidir, aynı rüyayı bir padişahın, vezirin ya da kadının görmesi ile 'āmme kavm görmesi arasında ya da alim ile cahilin görmesi arasında farklar olacaktır; bilgil kim at 'āmme kavm ve baht ve devletdür 8b/5, düşsde bal 'āmme kavme azcuk düzdür şehirliye çok düzdür 13a/19 diğer yandan zengin/fakir ayırımı da önemlidir; eger serçe bulsa yohsulısa altı akçadur baysa biy akçadur 29a/16; eger bir 'ālim saçın ḳıvırcık görse günāh ve azġınlıġıdur eger cāhil görse ululuġıdur 144b/13 vb. (Bayraktar,2019: 523-536).

kāfir, münāfik, müselmān, fāsı k gibi dinî sınıflandırmalar ile ata, ana, kardaş, ogul gibi akrabalık bağları olan kişi adları sık kullanılır; kız og̉lansa ve eger er og̀lansa 109b/18; 'torun' sözcüğü eserde geçmez': og்l og்ll 149b/20.

\footnotetext{
1 “torun” sözcüğ̈̈ Tarama Sözlüğ̈̈nde yer almamaktadrr. Gülensoy (2007b, 919) Köken Bilgisi sözlüğ̈̈nde torum: deve yavrusu sözcüğ̈̈ ile torun sözcüğ̈̈nü ilişkilendirerek Ermeniceden geldiğini söyleyen Eren ve Nişanyan'a karşı çıkmakta ve öz Türkçe olduğunu iddia etmektedir. Derleme Sözlüğünün 10. cildinde (Dikmen ve Bayaz, 1993: 3970) sözcük Giresun/Bulancak, Trabzon ve Rize ağızlarında 'yeğen' anlamında yer almaktadır.
} 
Eğer rüyayı bir kadının görme ihtimali varsa bu ayrıca izaha muhtaçtır: cābir magribî eydür șaru veyā aḳ 'avratlara eyüdür 95a/15 bezek 'avratlara erdür 152b/15, ne hālde görseler ta'bír 'avratlara dege 31b/15. Kadınlar 'avrat adıyla anılmaktadır. Erkeğin karısından bahsederken nadiren ' $1 y a ̄ l ~ 8 b / 4$ dendiği de olur. Eserde sadece bir kez eş adı kullanılmıştır; gerü eşin alsa 141a/2.

Erkeklerin rüyalarında kadınlar sıklıkla görülür, kadınlar öncelikle iki sınıftan oluşmaktadır: hür kadınlar ve karavaşlar yani hür olmayan kadınlar. Ancak kadınların sınıflandırılmaları bununla sınırlı kalmaz. Eserde son derece zengin bir sınıflandırma kullanılmıştır; arl dinlü 'avratdur 103a/1, asılsız 'avrat 95a/7, bikr 'avrat 103a/4, dindār 'avratdur 99a/16, hǖb 'avrat 91a/2, karl 'avratdur 100b/14, mesture 'avrat 113a/15, savaşcl 'avratdur 109b/3, saffetlü 'avrat 24b/16, ulu 'avrat 92b/19, yavuz'avrat 32a/7, yüklü 'avrat 24b/5, yüzsüz 'avrat 115a/19, yigit 'avrat 24b/2 vb. (Bayraktar, 2017:197-213).

Bir erkeğin rüyasının iyiye ya da kötüye yorumlanması erkeğin eşi olacak kadının zengin-fakir olmasına bağlı olabilir; avratından māl hāṣsl eyleye 98b/13, bir māllu 'avrat ala 8b/14, devekuşu düşde bir māllu 'avratdur 11a/6, bir yohsul 'avrat ala $99 \mathrm{~b} / 15$, vb.

Hür olmayan kadınlar da çağın gereği sosyal hayatta sıklıkla karşılaşılan bir gerçek olarak rüya yorumlarında kendisine yer bulmaktadır: 'acem ḳaravaşdur 95a/6, görklü ḳaravaş 27a/14, hüub ḳaravaşdur 98a/10, mestūre ḳaravaş 26a/4, oğul anası karavaşdur $102 \mathrm{~b} / 22 \mathrm{vb}$.

Yapılan yorumlardan rüya yorumcusunun kimi zaman bu topraklarda yaşadığını düşünebildiğimiz gibi kimi zaman da bunun mümkün olmadığını, rüya yorumlarının bir kısmının tercümeden ibaret olduğunu düşünmekteyiz. Söz gelimi muz yaprağını anlatırken Anadolu'da yaşayan bir kimsenin bunu hayatında görmemiş olacağı varsayılarak uzun uzadıya anlatılmasına karşın: degme yaprag bir namāzlağu gibi olur mıșırda çok olurmış 143b/13; Rüyada Hindistan cevizi görmekten sıradan bir vak'a gibi bahsedilmektedir. Osmanlı'nın başkenti olan İstanbul'da bu elbette mümkündür, ancak Anadolu'nun diğer şehirleri için rüyada Hindistan cevizi görmek şüphe götürür bir durumdur. çekirge çeridür eger bişmiş görse altun ve akçadur eger an yese çeriden nesne bula 142a/4-5 ifadesinde çekirge yemekten bahsetmektedir ki bu topraklarda alış1lagelen bir beslenme türü olduğu söylenemez. Yapı teknikleri ile ilgili özellikler de eserde yer bulmaktadır; büriyādan 
dìvār țutmaǵa zarlar tokusa 31b/17. Helal kazanmakla ilgili şu bilgi de dikkat çekicidir; elleri ditrese kazancında helāl ola ya ni eyü kazanmaya 132a/10.

Rüyada deve görmek, deveye binmek, deve köşkünde bulunmak, deve kurban etmek gibi çağımızda görülmesi, hayal edilmesi zor olan ama sadece bir asır önce muteber olan durumlar veya nesneler uzun uzun izah edilmişlerdir. Aynı şekilde at, eşek, katır gibi binek hayvanları, vahşi hayvanlar, kuşlar, çiftlik hayvanları, bunların renkleri, cinsiyetleri, bağırışları vb. pek çok unsur tâbirnâmenin maddeleri arasında yer almaktadır. at çağırsa, eşek a koyun üni, keçi oglak geyik ötdi, arslan üni, kaplan üni, ayu üni, kurt üni, it üni, toๆ uz üni, çakal, dilkü, sıçan, çetük, deve kuşı, kerkes, çakır toggan, dölengeç üni, şāhin tog̀an üni, bedinūs, saksagan, gögerçin, üvegi, bayg்uş, kumrı, süglün, țāvus, țurna, laḳlak, keklik, tavuḳ, karg̉a, ḳara ḳarga, bülbül, hezārdāstān, siğırçuḳ, ṣu ḳuşı, ördek, kaz, arı, çekirge, kurbaga üni eserde rüyalarda görüldüğü takdirde neye delalet ettiği ayrıntılı olarak izah edilmiştir. Bu nedenle de hangi hayvanın ses çıkarması nasıl adlandırılıyorsa burada bahsedilmiştir. hevāmm (böcekler, haşereler) karşılığ olarak Türkçe deprenür cānavārcuklar 152a/8 açıklaması uygun görülmüştür.

Ağaçlar madde başı yapıldığında (dıraḥtān 59b/19 maddesi); sözü geçen ağaç adları genel olarak Farsça ve Arapça iken, bu coğrafyaya mahsus bir kısmının da Rumca olduğu görülmektedir; hurma, abanoz, erük, armût, incīi, nār , üzüm, bādem, fülfül, ayva, pamuk, kendir, turunç, sögüt, hạzạl, zeytīn, 'unnāb, servi çınār, elma, şimşir, şeftālū, igde, fistık, findık kabak, patlıcan, kavun erganûn, gül, kiraz, gülnār, koz, Hindistan kozu, limon, mersin, hiyār, ḳavun, ḳarpuz olarak sıralanmıştır. Bu ağaçların yetiştikleri coğrafyaların muhtelif oluşları dikkatimizi çeker. Bugün ağaç olarak nitelemediğimiz yerden süren bitkilere ve sebzelere de eserde 'ağaç' dendiğini görmekteyiz. Tâbirnâmede bitki adları bakımından zengin bir içerikle karşılaşmaktayız, başlıkların Türkçe olmayıp ardından Türkçe açıklamalarının da veriliyor olması sözlüksel malzeme açısından önemlidir: sufüf: dāne-i ḥorasāni 83a/10, kāv-çeşm: öküz gözi derler bir çiçekdür $116 \mathrm{~b} / 7$, kāv-zebān: öküz dili derler bir ot olur 116b/10, mārçūbe: ilan bıçaği 134a/6, māz-1 keşişe: uruz otı134a/10, sakmuniya: mahmūde (bingöz otu) 82b/15, sežāb: maǵdenus 80a/15 ușturgàaz: devedikeni $11 \mathrm{a} / 8 \mathrm{vb}$.

Bugün mutfaklarımızda artık yer almayan pek çok yiyecek ve içecek adına eserde rast gelmekteyiz; ābkāme (Bağdat ve Anadolu'nun bazı doğu illerinde yapılan turşu ve salata nevinden katık) 111b/3, kāci (bulamaç)114b/13, kaliyye (tava kebabı) 113b/15, keşkāb (arpa çorbası)122a/9, zírebā: (kimyonlu aş) vb. Eserde bugün ayırt edilmiş bir şekilde kullanılan katı gıdalar yenir, sıvı gıdalar içilir ayırımı yapılmamış görülmektedir; eger gül suyun yese 123a/20, inek südi șagsa yese 116a/14. 
Yenebilecek sebze ve meyvelerin rüyada vakitli/ vakitsiz görülmesi yorumun olumlu/ olumsuz olmasina sebep olur; eger çubuk yeşil olursa vaktında yese işbu șfatlu 'avratdan hayr göre 69b/9, eger vaḳtında yese ol dükelü māldur 12a/19, vaktındaysa murāddur 12b/19, vakitsüz olsa șayrulukdur 14a/15 vb.

Mutfaklarda kullanılan kap kacak isimleri de zengindir; bedre: kova 67b/8, besat: yayvan kap 25b/8, hikk: tulum 59a/10, kabbān (büyük terazi, baskül) 112a/18, kınniye (büyük şişe, şarap kab1) 114a/21, sini 40a/17, teşt: legençe 39b/16 vb.

Giyecek adları çağının giyim tarzını bizlere sunmaktadır; 'itāb (kolsuz yakasız kadın gömleği) 112a/10, kefş: başmak 122b/18, makrame 141b/1, mıkna'a: bürüncük 141b/7, mūze: edük 143b/15, nemed: kepenek 149a/15. vāli maddesinde şehrin ileri gelenlerinin giyimi ile ilgili bir detay ilgi çekicidir; görsekim dülbendine bir dülbend dahı ulamışdur ululuğ $\dot{g}_{1}$ arta 149b/13

Madenlerden eserde siklıkla bahsedilmektedir, altun 28a/15, bakır 14a/4, demür 10a/8, gümüsş 28a/14, jiva 91a/20, kalāy $14 \mathrm{a} / 3$, pirinç $10 \mathrm{a} / 8$, sürb $81 \mathrm{~b} / 11$, sürünc $82 \mathrm{~b} /$, şebe $93 \mathrm{~b} / 9$, zırnih $75 \mathrm{~b} / 15$ vb. Rüyada görülen bir nesnenin hangi madenden imal edilmiş olduğu yapılacak yorumu doğrudan ilgilendirmektedir; ayağında demür bend var sefere gide ve anda eğlene, pirincden bend var nașrāníden așsı göre eger bakıırdan görse cuhüddan așș göre kalaydan görse kāfirden așș1 göre $30 \mathrm{a} / .$. vb. bunun yanında taş, ağaç (odun, kalas, tomruk vb.), pişmiş toprak ve sırça gibi maddelerden de nesneler rüyalarda görülür; eger sırçadandur 'avratlar șavaş eyleye eger kim taş yā demür bir tahılı un eylerdi...10a/9, dişleri gümüşden yã sırçadan yā sakssıdan olsa ecel yaḳındur $65 \mathrm{a} / 4$ eger ag̉açdan olsa șavaş eyleye $67 \mathrm{a} / 5$.

Rüyada görülen nesnelerin renkleri yorum için çok önemli bir ayrıntıdır. Sarı renk daima hastalık ile birlikte düşünülmüştür; ak müm olursa ḥelāl māldur eger șaru olursa șayrulukdur 144a/15, amrūd.. șaruysa șayrulukdur 12b/20, eger incir șarudur șayru ola 13a/5 vb. Ak ve yeşil renkler olumlu sonuçlara delildir; eger ag üzüm vaktında görse ni'met bula 14a/16, eger katırı aḳdur hū̄b yüzlü 'avratdur eger yeşil renglidür dini kaví 'avratdur 8b/15, vaktında görse yeşil olsa og̉uldur 30b/19, eger rengleri aḳ yā yeşil olsa 'avratlar șāliḥler olalar 43a/8, eger yeşildür borçı ödene $13 \mathrm{a} / 5 \mathrm{vb}$.

Kızıl ve kara renkler değişik yorumlara vesiledir; eger kızıl serçe görse hüb 'avrat ala yā görklü karavaș șatun ala 29a/14, eger ḳzıldur alıcı ve șatıcı' avratdur 8b/15, eger kıızl olursa 'işretçi olalar 43a/8, eger ḳaradur gușșadur13a/5, kızıl görse halā yıklar cengi ve kan dögmekdür kara olsa kahtlıḳdur 9b/14 vb. 


\section{SONUÇ ve DEĞERLENDIRME}

Eser 16. yüzyılda yazılmış olmasına rağmen Eski Anadolu Türkçesinin söz varlığını işlek olarak kullanmaktadır. Dizini üzerinde tarafımızdan çalışılmakta olan eserin söz varlığ kayda değer zenginliktedir. Sadece bu sebepten bile önemi büyük olan eser devrinin sosyo-kültürel alışkanlıklarına, inanış ve davranış kalıplarına dair sayısız bilgi sunmaktadır.

İnsanlığın geçmişteki bilgilerini sadece resmi tarihten öğrenemeyiz. Onun kültürel kodlarını, iç dünyasını, beklentilerini, ümitlerini ve korkularını, beğenilerini, becerilerini ve daha birçok konudaki fikirlerini öğrenebilmenin yollarından biri de hayallerine kulak vermektir. Hayallerine ait bilgilere en yakın mesafede de tâbirnâmeler olduğuna hiç şüphe yoktur. Çünkü bu tarz eserler rüyalarda görülmesi muhtemel durumları izah ederek çağının insanının iç dünyasını apaçık bizlere sunarken aynı zamanda kullandığı söz dağarcığı ile de dilbilimciler için yemyeşil bir vaha gibi karşımızda durmaktadır. Elimizdeki eser; Tābirü'lMenāmāt da bu anlamda gösterilecek her türlü ilgiyi hak eden yazı dili ile konuşma dilinin sınırlarını birlikte zorlayan bir eserdir.

KAYNAKÇA

Akçay, G. (2018). Mesnevilerde Rüya Teorileri. Türkbilig, (36), ss. 213-234. Ayrıca erişim: http://www.turkbilig.com/pdf/201836-581.pdf 08.09.2020.

Aksoy, Ö. A. \& Dilçin, D. (2009a). XIII. Yüzyıldan Beri Türkiye Türkçesiyle Yazılmış Kitaplardan Toplanan Tanıklarıyla Tarama Sözlüğü (A-B) I. Cilt, [4. Baskı]. Ankara: TDK Yayınları.

Aksoy, Ö. A. \& Dilçin, D. (2009b). XIII. Yüzyıldan Beri Türkiye Türkçesiyle Yazılmış Kitaplardan Toplanan Tanıklarıyla Tarama Sözlüğü (C-D) II. Cilt, [3. Baskı]. Ankara: TDK Yayınları.

Aksoy, Ö. A. \& Dilçin, D. (2009c). XIII. Yüzyıldan Beri Türkiye Türkçesiyle Yazılmış Kitaplardan Toplanan Tanıklarlyla Tarama Sözlüğü (E-İ) III. Cilt, [3. Bask1]. Ankara: TDK Yayınları.

Aksoy, Ö. A. \& Dilçin, D. (2009d). XIII. Yüzyıldan Beri Türkiye Türkçesiyle Yazılmış Kitaplardan Toplanan Tanıklarlyla Tarama Sözlüğ̈̈ (K-N) IV. Cilt, [3. Bask1]. Ankara: TDK Yayınları.

Aksoy, Ö. A. \& Dilçin, D. (2009e). XIII. Yüzyıldan Beri Türkiye Türkçesiyle Yazılmış Kitaplardan Toplanan Tanıklarıyla Tarama Sözlüğ̈̈ $(O-T)$ V. Cilt, [3. Bask1]. Ankara: TDK Yayınlar1.

Aksoy, Ö. A. \& Dilçin, D. (2009f). XIII. Yüzylldan Beri Türkiye Türkçesiyle Yazılmış Kitaplardan Toplanan Tanıklarılla Tarama Sözlüğ̈̈ (U-Z) VI. Cilt, [3. Baskı]. Ankara: TDK Yayınları.

Aksoy, Ö. A. \& Dilçin, D. (2009g). XIII. Yüzyıldan Beri Türkiye Türkçesiyle Yazılmış Kitaplardan Toplanan Tanıklarıyla Tarama Sözlüğü (Ekler) VII. Cilt, [3. Bask1]. Ankara: TDK Yayınları. 
Trakya Üniversitesi Sosyal Bilimler Dergisi

Haziran 2021 Cilt 23 Say1 1 (493-508)

Aksoy, Ö. A. \& Dilçin, D. (2009h). XIII. Yüzyıldan Beri Türkiye Türkçesiyle Yazılmış Kitaplardan Toplanan Tanıklarıyla Tarama Sözlüğ̈̈ (Dizin) VIII. Cilt, [3. Baskı]. Ankara: TDK Yayınları.

Balaban, A. (2014). Türkçe Yazma Tâbirnâmeler. Dil ve Edebiyat Eğitimi Dergisi, 9, ss.112-132 Ayrica erişim: https://www.academia.edu/7550564/T\%C3\%BCrk\%C3\%A7e_Yazma_Tabirnameler 08.09.2020.

Bars, M. E. (2015, Bahar). Türk Kültüründe Rüya ve Battal Gazi Destanı'nda İşlevleri. International Journal of Language Academy, 3(1), ss.73-93. DOI: 10.18033/ijla.194.

Baş, B. (2011, Bahar). Söz Varlığı ile İlgili Çalışmalarda Kullanılacak Ölçütler.

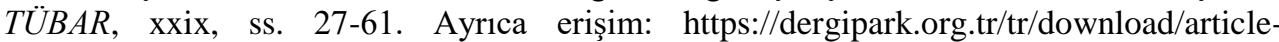
file/157052 08.09.2020.

Bayaz, A. (1993). Türkiye'de Halk Ă̆zından Derleme Sözlüğü (H-I) C. VII, [2. Bask1]. Ankara: TDK Yayınları.

Bayaz, A., Dikmen, A., Atabay, G., Barlas, A. (1993). Türkiye’de Halk Ağzından Derleme Sözlüğ̈̈ $(G) C$. VI, [2. Bask1]. Ankara: TDK Yayınları.

Bayraktar, F. S. (2019). Tâbirü'l Menâmât’ta Fakirlik Belirtisi Olan Rüyalar. İçinde E. Gürsoy Naskali (Ed.), Fakirlik, (ss. 523-536) İstanbul: Libra Yayınc1lık.

Bayraktar, F. S. (2017, Aralık). Tâbirü'l Menâmât'ta Kadının Toplumsal Cinsiyet Rolüne Bir Bakış. İçinde M. F. Köksal, M. Kaçar, M. İlhan (Ed.) Uluslararası Türk Dili ve Edebiyatında “Kadın” Sempozyumu, Amasya, 4-6 Mayıs 2017 [Bildiri Kitab1-Tam MetinElektronik Sürüm], 13, (ss. 197-213). Ankara: Amasya Üniversitesi Fen-Edebiyat Fakültesi adına Başkent Klişe Matbaacılı. Ayrıca erişim: https://www.academia.edu/41878438/T\%C3\%BCrk_Dili_ve_Edebiyat\%C4\%B1nda_Kad\% C4\%B1n_Sempozyumu 08.09.2020.

Bayraktaroğlu, G. (1993). Türkiye'de Halk Ağzından Derleme Sözlüğ̈̈ (E-F) C. V, [2. Bask1]. Ankara: TDK Yayınları.

Cankoçak-Akın, G. (1993). Türkiye’de Halk Ağgından Derleme Sözlüğ̈̈̈ (U-Z) C.

XI, [2. Bask1]. Ankara: TDK Yayınları.

Devellioğlu, F. (1980). Osmanlıca-Türkçe Ansiklopedik Lugat. Ankara: Doğuş Matbaası [4. Bask1].

Dikmen, A. \& Bayaz, A. (1993). Türkiye'de Halk A ğzından Derleme Sözlüğü $(S-T)$

C. $X,[2$. Baskı]. Ankara: TDK Yayınları.

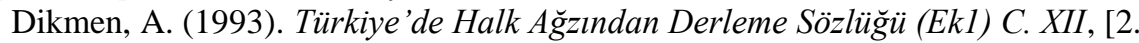

Bask1]. Ankara: TDK Yayınları.

Dikmen, A., Barlas, A., Bayraktaroğlu, G., Çıngı, A. (1993). Türkiye'de Halk

A ğzından Derleme Sözlüğ̈̈ (C-Ç) C. III, [2. Bask1]. Ankara: TDK Yayınları.

Dikmen, A., Tolluoğlu, M., Kutlar, P. (1993). Türkiye'de Halk A ğzından Derleme

Sözlüğü (K) C. VIII, [2. Bask1]. Ankara: TDK Yayınları.

Dilçin, C. (1983). Yeni Tarama Sözlüğ̈̈. Ankara: TDK Yayınları.

Gökyay, O. S.. (1982). Rüyalar Üzerine. İçinde II.Milletlerarası Türk Folklor Kongresi Bildirileri, C.IV, ss. 185- Ankara: MİFAD Yayınları. 
Gökyay, O. Ş., Coşkun, V. (2010). Tâbirnâme. TDV İslâm Ansiklopedisi. Cilt:39. s. 331-333.

Gülensoy, T. (2007a). Türkiye Türkçesindeki Türkçe Sözcüklerin Köken Bilgisi (A-N)

C.1. Ankara: TDK Yayınları.

Gülensoy, T. (2007b). Türkiye Türkçesindeki Türkçe Sözcüklerin Köken Bilgisi (O-Z)

C.2. Ankara: TDK Yayınları.

Kartallığlu, Y. (2017). Osmanlı Konuşma Dili. İstanbul: Kesit Yayınları. Yayınları.

Levend, A. S. (1988). Türk Edebiyatı Tarihi. C.1, Ankara: Türk Tarih Kurumu

Osmanlıca Türkçe Sözlük. (t.y.). Erişim adresi: www.osmanlicaturkce.com 08.09.2020.

Önler, Z. (1999). Müntahab-ı Şifâ Sözlük. C. II. İstanbul: Simurg Yayınları.

Öztürk, M. (2000) Burhân-ı Katı- Mütercim Âsım Efendi, Ankara: TDK Yayınları.

Parlatır, İ., Gözaydın, N., Zülfikar, H., Aksu-Tezcan, B., Türkmen, S., Yılmaz, Y. (1998). Büyük Türkçe Sözlük, [9. Baskı]. Ankara: TDK Yayınları.

Şahin, H. (2003). Eski Anadolu Türkçesi. Ankara: Akçağ Yayınları.

Şahin, H. (2007) CÀmi'ü'l-Fürs Örneğinde XVI. Yüzyıl Bitki İsimleri. Turkish Studies, 2(2), $\quad$ ss. 571-602. Ayrıca erişim: https://arastirmax.com/en/system/files/dergiler/79199/makaleler/2/2/arastirmax-camiulfurs-orneginde-xvi.yuzyil-bitki-isimleri.pdf 08.09.2020.

Tatçı, M. \& Çeltik, H. (1995). Türk Edebiyatında Tasavvufi Rüya Tâbirnâmeleri. Ankara: Akçă̆ Yayınları.

Tören, H. (1997). Ta'bür-nāme. Türkiyat Mecmuası, 20(0), ss. 415-452. Ayrıca erişim: https://dergipark.org.tr/tr/download/article-file/172624 08.09.2020.

Ülkütaşır, Ş., Ünver, A., Vardarlı, E., Cankoçak, G., Cankoçak, Y., Sarıbaş, O. (1993). Türkiye'de Halk Ağzından Derleme Sözlüğ̈̈ (A) C. I, [2. Baskı]. Ankara: TDK Yayınları.

Vardarl, E. (1993a). Türkiye'de Halk A ̆gzindan Derleme Sözlüğ̈̈ (D) C. IV, [2. Bask1]. Ankara: TDK Yayınları.

Vardarl1, E. (1993b). Türkiye'de Halk Ağzlndan Derleme Sözlüğ̈̈ (L-R) C. IX, [2. Bask1]. Ankara: TDK Yayınları.

Vardarlı, E., Ülkütaşır, Ş., Ünver, A., Cankoçak, G., Sarıbaş, O., Dilçin, C. (1993).

Türkiye'de Halk A ̆gzından Derleme Sözlüğ̈̈ (B) C. II, [2. Baskı]. Ankara: TDK Yayınları.

Yılmaz, K. \& Çetin, K. (2007, Güz). Rüyalar ve Niyazî-i Mısrî'nin Ta'bîrÀtü'lVÀkı'Àt Adlı Eserinde Rüyaların Dili. Turkish Studies, 2(4), ss.1066-1076. Ayrıca erişim: http://www.turkishstudies.net/DergiTamDetay.aspx?ID=215 08.09.2020. 